Research Article

\title{
Energy Absorption Characteristics of Frozen Soil Based on SHPB Test
}

\author{
Qin-yong Ma $\mathbb{D}^{D}$, Dong-dong Ma ${ }^{(D)}$, Pu Yuan $\mathbb{D}^{D}$, and Zhao-ming Yao \\ Research Center of Mine Underground Engineering, Ministry of Education, Anhui University of Science and Technology, \\ Huainan, Anhui 232001, China \\ Correspondence should be addressed to Dong-dong Ma; dongdonm@126.com
}

Received 23 November 2017; Revised 2 February 2018; Accepted 11 February 2018; Published 20 March 2018

Academic Editor: Hongchao Kou

Copyright (C) 2018 Qin-yong Ma et al. This is an open access article distributed under the Creative Commons Attribution License, which permits unrestricted use, distribution, and reproduction in any medium, provided the original work is properly cited.

Dynamic compressive tests are performed in three frozen soil types under different stress states at freezing temperatures of $-5^{\circ} \mathrm{C}$ and $-15^{\circ} \mathrm{C}$ with impact loading pressures from $0.3 \mathrm{MPa}$ to $0.6 \mathrm{MPa}$. The effects of frozen soil type, freezing temperature, impact loading pressures, and stress states on incident energy and energy absorption characteristics, such as absorbed energy and energy absorbency rate, are investigated. The experimental results show that most of the incident energy is reflected back to the incident bar, and incident energy linearly increases with the increase of impact loading pressures. Both absorbed energy and energy absorbency rate are found to be negatively correlated with freezing temperature, and there values under confining pressure state are larger than that under uniaxial condition. The effects of confining pressure on absorbed energy are quite different at different freezing temperatures. In addition, frozen soil type also affects absorbed energy and energy absorbency rate. Meanwhile, impact loading pressure shows an increased effect on the absorbed energy, but it has little effect on energy absorbency rate in the research.

\section{Introduction}

About $24 \%$ vast regions of the world's land is permafrost [1], and a number of construction projects, such as highways, tunnels, and mines, are constructed in cold regions. Many frozen soil engineering activities in underground, such as mining excavation and tunnel excavation, always involve frozen soil responses to impact loading, and dynamic mechanical property is one of the most important components of mechanical property of frozen soil [2]. Hence, it is significant to study the dynamic behavior of frozen soil. Many studies have focused on the dynamic behavior of frozen soil and acquired abundant accomplishments [3-5]. Effect factors, such as strain rate, freezing temperature, and water content on the dynamic deformation behaviors and strength of frozen soil, have been investigated in the previous study. To improve the excavation efficiency of frozen soil in cold regions, with the help of the split Hopkinson pressure bar (SHPB) device, the dynamic mechanical behavior of frozen soil under different freezing temperature and strain rates is studied
[5]. And test results show that frozen soil exhibits temperature effect and strain rate effect, and failure type tends to change from plastic failure to brittle failure with increasing of strain rate or decreasing of temperature. Meanwhile, the corresponding constitutive models have been proposed with different methods based on stressstrain relationship [6-8].

The laws of thermodynamics reveal that energy conversion is the basic rule of physical processes of materials. The damage and failure of material are accompanied with accumulation, dissipation, and release of energy $[9,10]$. At present, the worldwide studies on energy absorption characteristics under impact loading mainly focus on rock [11, 12], cement [13], metal [14], and porous materials [15-17]. The inoculation, germination, extension, and connection of microcracks inside frozen soil lead to the deformation and failure of frozen soil with energy accumulation and dissipation [18]. Energy dissipation reflects the evolution of the internal defects, which leads to strength weakening of frozen soil. Studies of the energy absorption characteristics of frozen soil under impact 
loading are of great significance to determine the blasting parameters as well as for safe and efficient production in cold regions.

However, the theoretical and experimental research on dynamic mechanical behavior of frozen soil cited above primarily concentrates on mechanical behavior but in shortage of energy absorption characteristics. Furthermore, few studies have focused on the effect of frozen soil type on dynamic energy absorption characteristics of frozen soil. However, those factors, such as frozen soil type, freezing temperature, and stress state, have significant effect on the selection of blasting parameters in frozen soil crushing engineering. Studying the effects of different test parameters on energy absorption characteristics of frozen soil contributes to improve the crushing efficiency in cold regions. In this work, three frozen soil types are used as subjects, and SHPB tests are performed to investigate the energy absorption characteristics of the frozen soil. Tests are conducted under different stress states at freezing temperatures of $-5^{\circ} \mathrm{C}$ and $-15^{\circ} \mathrm{C}$ with impact loading pressures from $0.3 \mathrm{MPa}$ to $0.6 \mathrm{MPa}$. The effects of test parameters on incident energy and energy absorption characteristics, including absorbed energy and energy absorbency rate, are investigated in this research so as to provide some experimental evidence for blasting design in frozen soil crushing engineering.

\section{Test Preparation and Energy Calculation}

2.1. Analysis of Data Reliability and Specimen Preparation. Split Hopkinson pressure bar (SHPB) with a diameter of $50 \mathrm{~mm}$ is adopted in this paper, as shown in Figure 1. The SHPB device contains a pulse shaper, a striker bar, an incident bar, a transmitted bar, a confining pressure device, and an acquisition system. The length of the striker, the incident bar, and the transmitted bar are $600 \mathrm{~mm}, 2400 \mathrm{~mm}$, and $1200 \mathrm{~mm}$, respectively, and they are made of high-strength alloy steel with $210 \mathrm{GPa}$ Young's modulus and $7900 \mathrm{~kg} / \mathrm{m}^{3}$ density. A strain gauge is mounted on the incident bar to record the incident and reflected waves, and a semiconductor strain gauge is mounted on the transmitted bar to record the transmitted wave because of the low wave impedance of the frozen soil specimen.

To achieve the uniform stress hypothesis in SHPB tests, four approaches are adopted to enhance the data reliability:

(1) The optimized slenderness ratio of frozen soil specimens of 0.5 is selected [19].

(2) Appropriate lubricant is evenly smeared on the surface of the frozen soil specimen to reduce the end surface friction between frozen soil specimen and bars.

(3) The carton pulse shaper with $0.8 \mathrm{~mm}$ thick and $5 \mathrm{~mm}$ diameter is placed on the impact surface of the incident bar [20].

(4) The end of the incident bar adopts the straight tapered transition form, which is beneficial to the stress equilibrium of the frozen soil specimen.

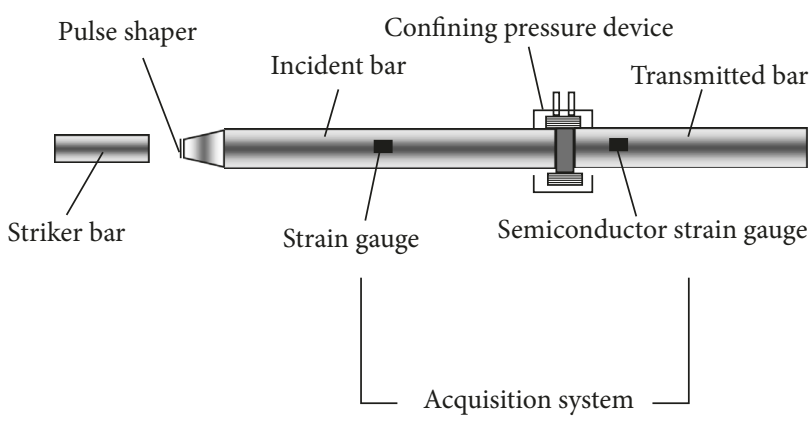

FIgURE 1: Split Hopkinson pressure bar.

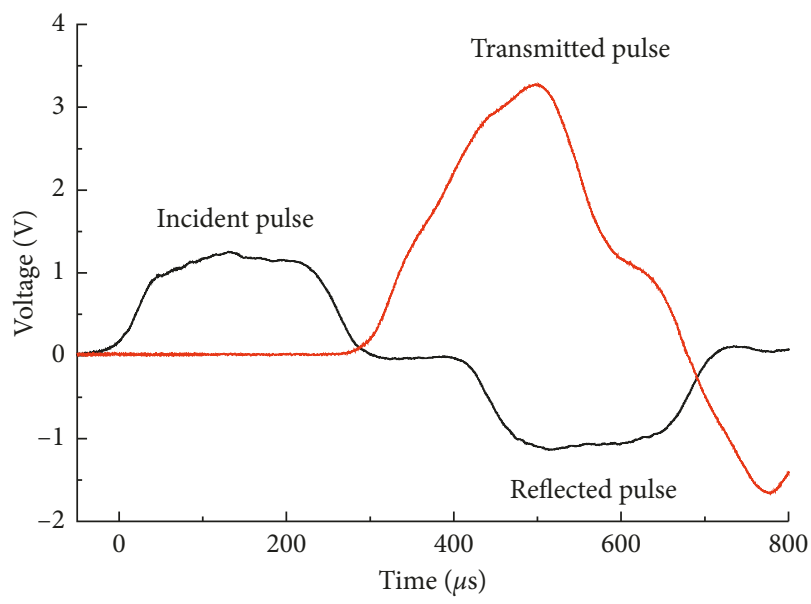

Figure 2: Typical shaped waveforms.

The SHPB test steps are as follows:

(1) Check all the test devices on the working condition and make sure all the pressure bars on the same plane.

(2) Appropriate lubricant is evenly smeared on the surface of frozen soil specimen, and then put the frozen soil between the incident bar and transmitted bar.

(3) Open the acquisition system, set the test gas pressure, and press the air pressure switch.

(4) Collect the fragment of the frozen soil specimen.

The typical shaped waveforms measured in SHPB tests are shown in Figure 2. From Figure 2, it is clearly noticed that sine wave pattern loading is achieved and the waveform is smooth. Detailed explanations and demonstrations on the test apparatus of confining pressure equipment have been introduced [7].

The test frozen soil specimens are collected from a coalmine in Jining, Shandong province. Sampling conditions and particle size distribution of three types of frozen soil are shown in Tables 1 and 2, respectively.

The preparation procedures of the frozen soil sample are as following:

(1) Treatment of undisturbed clay. The undisturbed clay is crushed down with a wooden hammer, and the 
TABLE 1: Sampling conditions in three types of soil.

\begin{tabular}{lcccc}
\hline Specimen group & Type of frozen soil & Depth selection $(\mathrm{m})$ & Water content & Dry density $\left(\mathrm{g} / \mathrm{cm}^{3}\right)$ \\
\hline Group A & Clay & $54.2 \sim 54.4$ & $19.28 \%$ & 1.78 \\
Group B & Sandy soil & $94.8 \sim 94.9$ & $12.14 \%$ & 1.38 \\
Group C & Floury soil & $274.4 \sim 274.6$ & $16.36 \%$ & 1.38 \\
\hline
\end{tabular}

TABLe 2: Particle size distribution in three types of frozen soil.

\begin{tabular}{lccccc}
\hline Specimen group & $1.25 \sim 2.5(\mathrm{~mm})$ & $0.63 \sim 1.25(\mathrm{~mm})$ & $0.315 \sim 0.63(\mathrm{~mm})$ & $0.071 \sim 0.315(\mathrm{~mm})$ & $0 \sim 0.071(\mathrm{~mm})$ \\
\hline Group A & $27.5 \%$ & $26.7 \%$ & $19.6 \%$ & $16.6 \%$ & $9.6 \%$ \\
Group B & $13.0 \%$ & $23.9 \%$ & $31.5 \%$ & $21.1 \%$ & $10.5 \%$ \\
Group C & $14.7 \%$ & $17.3 \%$ & $20.2 \%$ & $34.1 \%$ & $13.7 \%$ \\
\hline
\end{tabular}

grains with size larger than $2.5 \mathrm{~mm}$ are sifted out from the sample by sieve.

(2) Treatment of drying. The sifted clay is put in a dryer at $105^{\circ} \mathrm{C}$ for more than $12 \mathrm{~h}$.

(3) Preparation process of frozen soil specimen. An appropriate amount of distilled water is added into the dry clay and mixed uniformly, and then the clay is stored in a closed container for more than $24 \mathrm{~h}$ to make soil particle evenly containing water; after that the soil is placed into a compacting instrument with an inner diameter of $50 \mathrm{~mm}$ and a height of $25 \mathrm{~mm}$ at least three times.

(4) Treatment of freezing. The well-made clay specimens are placed in a refrigerator at $-20^{\circ} \mathrm{C}$ for more than $24 \mathrm{~h}$, and then put it at the desired freezing temperature for more than $24 \mathrm{~h}$.

2.2. Principles of Energy Calculation. Based on the onedimensional stress wave theory and the assumption of uniform stress [21], the stress-strain and strain rate can be calculated through $(1 \sim 3)$ :

$$
\begin{aligned}
& \sigma(t)=\frac{E_{0} A_{0}}{A_{s}} \varepsilon_{\mathrm{T}}(t), \\
& \varepsilon(t)=\frac{C_{0}}{l_{s}} \int_{0}^{\tau}\left[\varepsilon_{\mathrm{I}}(t)-\varepsilon_{\mathrm{R}}(t)-\varepsilon_{\mathrm{T}}(t)\right] d t, \\
& \dot{\varepsilon}(t)=\frac{C_{0}}{l_{s}}\left[\varepsilon_{\mathrm{I}}(t)-\varepsilon_{\mathrm{R}}(t)-\varepsilon_{\mathrm{T}}(t)\right],
\end{aligned}
$$

where $\varepsilon_{\mathrm{I}}(t), \varepsilon_{\mathrm{R}}(t)$, and $\varepsilon_{\mathrm{T}}(t)$ are incident wave, reflected wave, and transmitted wave, respectively; $E_{0}, A_{0}$, and $C_{0}$ are Young's modulus, the cross-sectional area, and the elastic wave speed of the bar, and $A_{s}$ and $l_{s}$ are the cross-sectional area and height of the frozen soil specimen, respectively; $t$ is the duration time of elastic wave.

In addition, incident energy, reflected energy, and transmitted energy can be calculated through the following equation:

$$
W_{i}=\frac{A_{0} C_{0}}{E_{0}} \int \sigma_{i}^{2}(t) d t, \quad i=\mathrm{I}, \mathrm{R}, \mathrm{T},
$$

where $\sigma_{\mathrm{I}}(t), \sigma_{\mathrm{R}}(t)$, and $\sigma_{\mathrm{T}}(t)$ are the stress of incident wave, reflected wave, and transmitted wave, respectively.

If the energy loss between the frozen soil specimen and bars is ignored, the absorption energy $W_{\mathrm{S}}(t)$ can be calculated through the following equation:

$$
W_{\mathrm{S}}(t)=W_{\mathrm{I}}(t)-W_{\mathrm{R}}(t)-W_{\mathrm{T}}(t) .
$$

In addition, the energy absorbency rate $\left(w_{\mathrm{d}}\right)$ is adopted and defined as the ratio between the absorbed energy and the incident energy, as shown in the following equation:

$$
w_{\mathrm{d}}=\frac{W_{\mathrm{S}}}{W_{\mathrm{I}}} \times 100 \% \text {. }
$$

The SHPB test design for three types of frozen soil under different test conditions is shown in Table 3.

\section{Test Results and Discussion}

3.1. Analysis of Energy-Time Curve and Incident Energy. The representative energy-time curve of the frozen soil specimen obtained through calculation is shown in Figure 3. Figure 3 indicates that, from 0 to $250 \mu \mathrm{s}$, the incident energy and the reflected energy increase rapidly compared with the transmitted energy and absorbed energy with the propagation of stress wave and their values maintain stable after reaching a certain value, and the appearance of maximum absorption energy indicates the failure of the frozen soil specimen [9]. Table 4 shows the test results of energy distribution for frozen soil, including final incident energy, absorbed energy, reflected energy, transmitted energy and the percentage value of each test. Table 4 shows that most of incident energy is reflected because of the relatively low wave impedance of frozen soil.

Because the generation of incident energy is caused by the impact between the striker bar and incident bar, the value of incident energy is only determined by the velocity of the impact bar. In this study, impact loading pressures are the single factor, and other factors, such as stress state, freezing temperature, and frozen soil type, have no effect on the incident energy. The relationship between impact loading pressures and incident energy for three types of frozen soil is shown in Figure 4. Figure 4 reveals that the 
TABLE 3: SHPB test design for three types of frozen soil.

\begin{tabular}{|c|c|c|c|c|}
\hline Specimen group & Type of soil & Impact loading pressure $(\mathrm{MPa})$ & Stress state & Freezing temperature $\left({ }^{\circ} \mathrm{C}\right)$ \\
\hline \multirow{3}{*}{ Group A } & \multirow{3}{*}{ Clay } & 0.3 & Confining pressure of $0.5 \mathrm{MPa}$ & $\begin{array}{c}-5 \\
-15\end{array}$ \\
\hline & & 0.45 & Confining pressure of $0.5 \mathrm{MPa}$ & $\begin{array}{c}-5 \\
-15\end{array}$ \\
\hline & & 0.6 & Confining pressure of $0.5 \mathrm{MPa}$ & $\begin{array}{c}-5 \\
-15\end{array}$ \\
\hline Group B & Sandy soil & 0.45 & $\begin{array}{c}\text { Uniaxial condition } \\
\text { Confining pressure of } 0.5 \mathrm{MPa}, 1.0 \mathrm{MPa} \text {, } \\
1.5 \mathrm{MPa} \text {, and } 2.0 \mathrm{MPa}\end{array}$ & $\begin{array}{l}-5 \\
-15 \\
-5 \\
-15\end{array}$ \\
\hline Group C & Floury soil & 0.45 & Confining pressure of $0.5 \mathrm{MPa}$ & $\begin{array}{c}-5 \\
-15\end{array}$ \\
\hline
\end{tabular}

incident energy $\left(W_{\mathrm{I}}\right)$ increases with the increase of impact loading pressures, which exhibits a linear correlation.

3.2. Analysis of Absorbed Energy. In this research, four test parameters, including frozen soil type, freezing temperature, impact loading pressures, and stress state, are taken into consideration on the energy absorption characteristics. Therefore, the simple variable method is adopted to analyze the relationships between the absorbed energy and test parameters.

The absorbed energy under different test conditions has been calculated and the relationships among impact loading pressures, stress state, and freezing temperature with the absorbed energy are shown in Figures 5 and 6. From these figures, conclusions can be summarized as follows. (1) The absorbed energy is influenced by impact loading pressures, freezing temperature, and stress state. (2) Group A shows that the absorbed energy generally increases with the increase of impact loading pressures and the decrease of freezing temperature. The effects of impact loading pressures on the absorbed energy are quite different at different freezing temperatures; for example, the average value of absorbed energy increases from $2.74 \mathrm{~J}$ to $6.24 \mathrm{~J}$ with impact loading pressures increasing from $0.3 \mathrm{MPa}$ to $0.6 \mathrm{MPa}$ at $-5^{\circ} \mathrm{C}$ and the corresponding values change from $8.12 \mathrm{~J}$ to $21.83 \mathrm{~J}$ at $-15^{\circ} \mathrm{C}$. The growth value of absorbed energy is $13.71 \mathrm{~J}$ at $-15^{\circ} \mathrm{C}$, which is much higher than that of $3.50 \mathrm{~J}$ at $-5^{\circ} \mathrm{C}$. (3) The effects of confining pressure on absorbed energy are quite different at $-5^{\circ} \mathrm{C}$ and $-15^{\circ} \mathrm{C}$. At $-5^{\circ} \mathrm{C}$, the absorbed energy presents a change of first increase then decrease; in detail, the average absorbed energy increases from $7.08 \mathrm{~J}$ (uniaxial condition) to $12.31 \mathrm{~J}$ (confining pressure of $1.5 \mathrm{MPa}$ ), and then it has a minor reduction to $11.46 \mathrm{~J}$ (confining pressure of $2.0 \mathrm{MPa}$ ). At $-15^{\circ} \mathrm{C}$, the average absorbed energy of frozen soil linearly increases with the increase of confining pressure. The mechanism behind this phenomenon can be clarified as follows. In this test, the static compressive strengths of Group $\mathrm{B}$ are $1.51 \mathrm{MPa}$ and $3.12 \mathrm{MPa}$ at $-5^{\circ} \mathrm{C}$ and $-15^{\circ} \mathrm{C}$, respectively. When the value of confining pressure is relatively smaller than the strength of artificial frozen soil, the increase of confining pressure results in the thaw of ice within frozen soil [1]. Hence, under the same incident energy, both the number of cracks inside

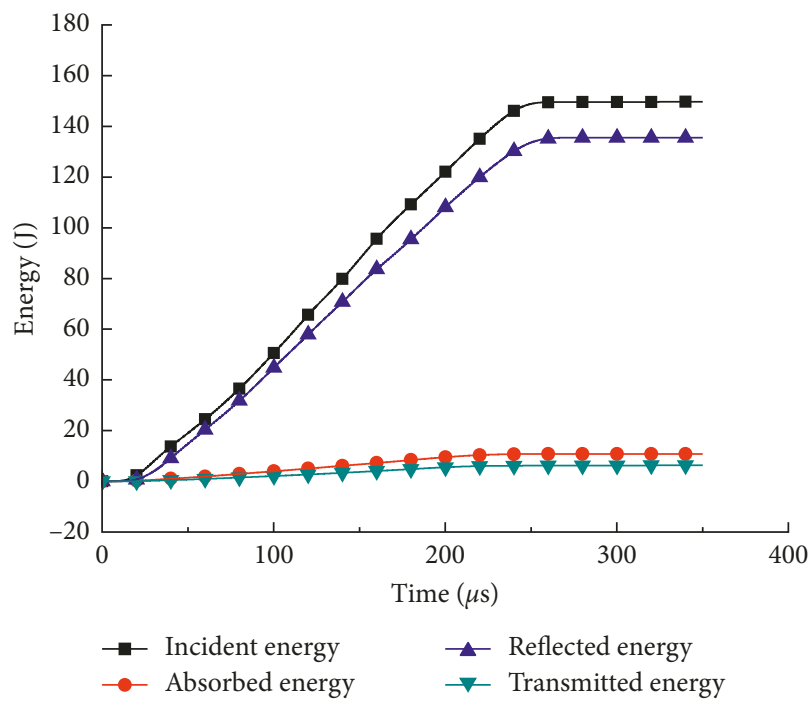

Figure 3: Energy-time curve of sandy soil (Group B) at $-5^{\circ} \mathrm{C}$ under a confining pressure of $0.5 \mathrm{MPa}$.

the frozen soil and its propagation increase with the increase of confining pressure. In addition, the larger confining pressure facilitates the axial direction deformation of frozen soil, which also leads to the increase of absorbed energy. When the value of confining pressure is higher than the strength of artificial frozen soil, the inner structure of artificial frozen soil is destroyed $[1,18]$, leading to the decrease of absorbed energy, which is corresponding to the descent stage at $-5^{\circ} \mathrm{C}$ in Figure 6 .

The comparison of average absorbed energy for three groups of frozen soil is illustrated in Figure 7. Figure 7 reveals that the type of frozen soil has an effect on the average value of absorbed energy, and the ranking is quite different at $-5^{\circ} \mathrm{C}$ and $-15^{\circ} \mathrm{C}$. At $-5^{\circ} \mathrm{C}$, Group $\mathrm{B}$ has the maximum value followed by Group $\mathrm{C}$ and then Group A. However, at $-15^{\circ} \mathrm{C}$, Group $\mathrm{C}$ shows the maximum value following group $\mathrm{B}$ and then group $\mathrm{A}$.

3.3. Analysis of Energy Absorbency Rate. The energy absorbency rate represents the absorption efficiency of frozen soil 
TABLE 4: Test results of the energy distribution of frozen soil.

\begin{tabular}{|c|c|c|c|c|c|c|c|}
\hline \multirow{2}{*}{ Specimen number } & \multirow{2}{*}{ Incident energy $(\mathrm{J})$} & \multicolumn{2}{|c|}{ Absorbed energy $(\mathrm{J})$} & \multicolumn{2}{|c|}{ Reflected energy (J) } & \multicolumn{2}{|c|}{ Transmitted energy (J) } \\
\hline & & Value $(J)$ & Percentage & Value $(\mathrm{J})$ & Percentage & Value $(J)$ & Percentage \\
\hline A-0.3-5-1 & 78.56 & 2.60 & 3.31 & 71.49 & 91.01 & 4.47 & 5.69 \\
\hline A-0.3-5-2 & 81.45 & 2.75 & 3.38 & 75.75 & 93.00 & 2.98 & 3.66 \\
\hline A- $0.3-5-3$ & 81.50 & 2.74 & 3.36 & 75.14 & 92.20 & 3.62 & 4.44 \\
\hline A- $0.3-5-4$ & 70.25 & 2.87 & 4.09 & 63.23 & 90.01 & 4.16 & 5.92 \\
\hline A- $-0.45-5-5$ & 137.20 & 4.65 & 3.39 & 126.22 & 92.00 & 6.33 & 4.61 \\
\hline A- $0.45-5-6$ & 148.20 & 5.00 & 3.37 & 133.23 & 89.90 & 9.97 & 6.73 \\
\hline A-0.6-5-7 & 195.04 & 6.73 & 3.45 & 169.68 & 86.99 & 18.64 & 9.56 \\
\hline A- $0.6-5-8$ & 188.35 & 5.75 & 3.05 & 171.40 & 90.01 & 11.20 & 5.95 \\
\hline A-0.3-15-9 & 61.82 & 8.69 & 14.06 & 51.78 & 83.76 & 1.35 & 2.18 \\
\hline A- $-0.3-15-10$ & 64.98 & 7.54 & 11.60 & 55.23 & 84.98 & 2.21 & 3.40 \\
\hline A- $-0.3-15-11$ & 66.87 & 8.07 & 12.07 & 57.17 & 85.49 & 1.63 & 2.44 \\
\hline A- $0.3-15-12$ & 72.67 & 8.17 & 11.24 & 62.50 & 86.01 & 2.00 & 2.75 \\
\hline A- $-0.45-15-13$ & 124.93 & 16.84 & 13.48 & 105.34 & 84.32 & 2.75 & 2.20 \\
\hline A- $0.45-15-14$ & 135.79 & 15.73 & 11.58 & 116.78 & 86.00 & 3.28 & 2.42 \\
\hline A-0.6-15-15 & 208.45 & 23.59 & 11.32 & 175.04 & 83.97 & 9.82 & 4.71 \\
\hline A- $-0.6-15-16$ & 207.16 & 20.07 & 9.69 & 183.41 & 88.54 & 3.68 & 1.78 \\
\hline B- $0.45-5-1$ & 124.48 & 6.97 & 13.71 & 110.79 & 89.01 & 6.72 & 5.40 \\
\hline B- $0.45-5-2$ & 143.25 & 7.18 & 13.85 & 131.25 & 91.62 & 4.82 & 3.36 \\
\hline B- $0.45-5-3$ & 149.68 & 10.75 & 7.18 & 135.59 & 90.58 & 6.30 & 4.21 \\
\hline B- $0.45-5-4$ & 124.92 & 10.10 & 18.80 & 112.93 & 90.40 & 1.89 & 1.51 \\
\hline B- $0.45-5-5$ & 129.91 & 10.75 & 19.18 & 117.22 & 90.23 & 1.94 & 1.49 \\
\hline B- $0.45-5-6$ & 124.14 & 11.22 & 18.02 & 110.46 & 88.98 & 2.46 & 1.98 \\
\hline B- $0.45-5-7$ & 125.00 & 12.26 & 23.54 & 113.89 & 91.11 & 1.15 & $0.92 \%$ \\
\hline B- $0.45-5-8$ & 127.91 & 12.36 & 13.71 & 111.28 & 86.99 & 15.27 & 11.94 \\
\hline B- $0.45-5-9$ & 115.13 & 12.15 & 13.85 & 101.58 & 88.23 & 1.40 & 1.22 \\
\hline B- $0.45-5-10$ & 119.69 & 10.76 & 17.65 & 106.17 & 88.70 & 2.76 & 2.31 \\
\hline B- $0.45-15-11$ & 123.00 & 19.47 & 13.71 & 101.60 & 82.60 & 1.93 & 1.57 \\
\hline B- $0.45-15-12$ & 136.55 & 20.67 & 13.85 & 114.99 & 84.21 & 0.89 & 0.65 \\
\hline B- $0.45-15-13$ & 119.25 & 22.73 & 17.65 & 95.41 & 80.01 & 1.11 & 0.93 \\
\hline B- $0.45-15-14$ & 134.95 & 24.34 & 18.80 & 109.57 & 81.19 & 1.04 & 0.77 \\
\hline B- $0.45-15-15$ & 138.70 & 24.96 & 19.18 & 112.95 & 81.43 & 1.21 & 0.87 \\
\hline B- $0.45-15-16$ & 125.98 & 27.38 & 18.02 & 106.67 & 84.67 & 8.07 & 6.41 \\
\hline B- $0.45-15-17$ & 138.91 & 32.10 & 23.54 & 104.05 & 74.90 & 2.76 & 1.99 \\
\hline C- $0.45-5-1$ & 131.72 & 9.02 & 6.85 & 119.87 & 91.00 & 2.83 & 2.15 \\
\hline C- $0.45-5-2$ & 127.19 & 8.34 & 6.56 & 116.12 & 91.31 & 2.73 & 2.15 \\
\hline C- $0.45-5-3$ & 136.39 & 8.20 & 6.01 & 125.34 & 91.89 & 2.85 & 2.09 \\
\hline C- $0.45-15-4$ & 117.95 & 28.61 & 24.26 & 88.08 & 74.68 & 1.26 & 1.07 \\
\hline C- $0.45-15-5$ & 127.21 & 28.81 & 22.65 & 97.67 & 76.78 & 6.73 & 5.29 \\
\hline
\end{tabular}

Note. Specimen number A-0.3-5-1 stands for the group of A, the $0.3 \mathrm{MPa}$ impact loading pressure, and $-5^{\circ} \mathrm{C}$ freezing temperature.

under dynamic loading, which is an important engineering design parameter in frozen soil crushing engineering. Hence, it is significant to investigate the effects of test parameters on the energy absorbency rate.

Based on (6), it is noticed that the change of the absorption energy $W_{\mathrm{S}}$ and the energy absorbency rate $w_{\mathrm{d}}$ is consistent for different confining pressures and different groups of artificial frozen soil. Therefore, the influence of confining pressure and groups of artificial frozen soil on energy absorbency rate $w_{\mathrm{d}}$ can be obtained from Figures 6 and 7 and Table 4. The measured energy absorbency rate of frozen soil under different impact loading pressures is illustrated in Figure 8. The effects of them on the energy absorbency rate are investigated.

Figures 6-8 and Table 4 reveal that (1) for Group A, the average values of energy absorbency rate have little changes while the impact loading pressures increase from $0.3 \mathrm{MPa}$ to $0.6 \mathrm{MPa}$. For example, at $-5^{\circ} \mathrm{C}$, the average

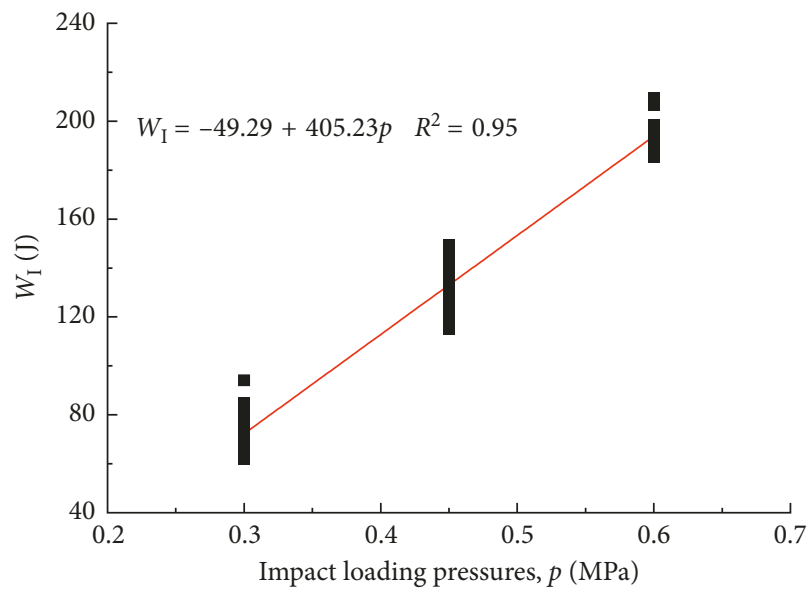

FIGURE 4: Relation between impact loading pressures and incident energy. 


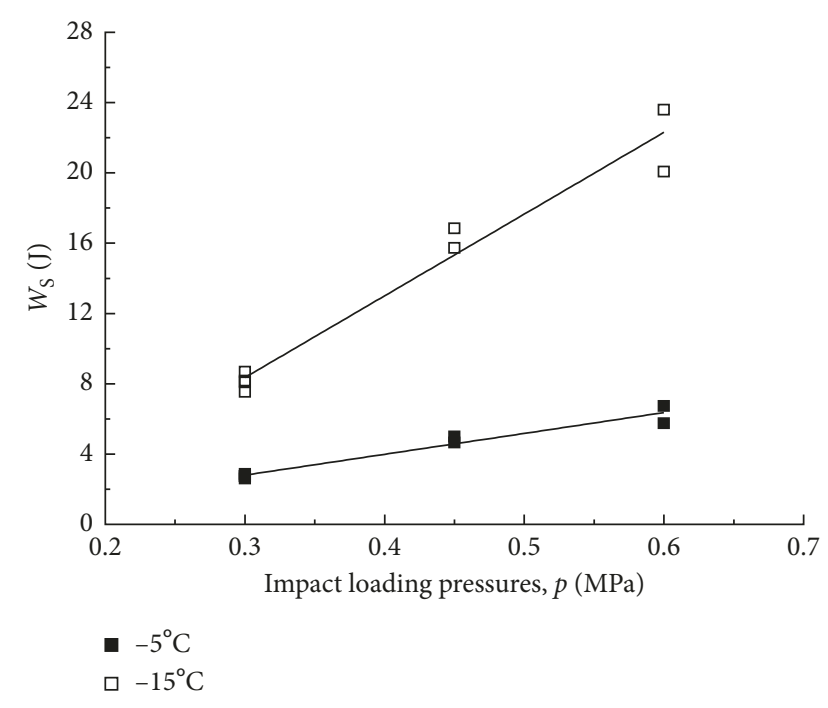

Figure 5: Absorbed energy of Group A under different test conditions.

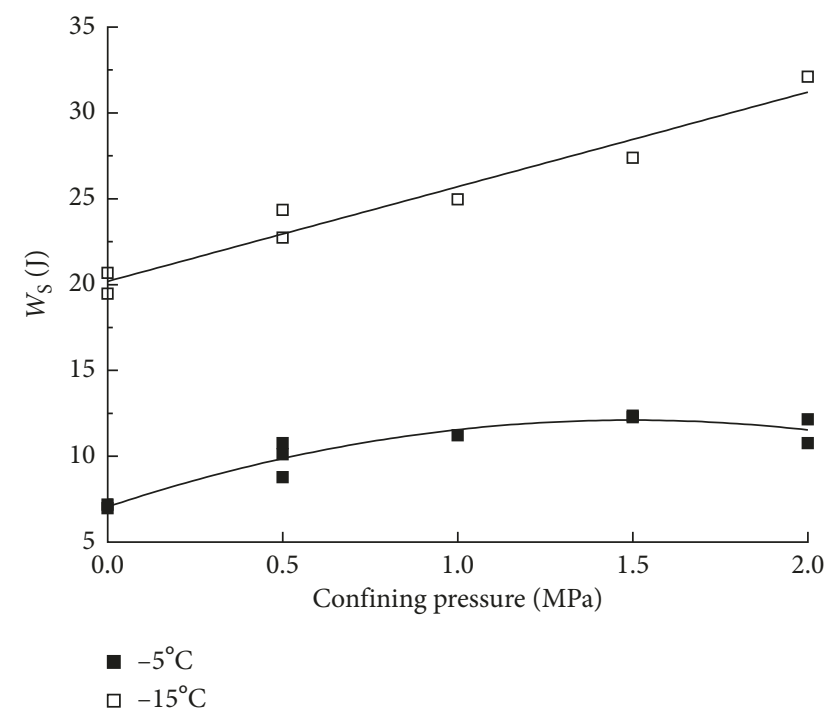

Figure 6: Absorbed energy of Group B under different test conditions.

values of the energy absorbency rate under the impact loading pressures of $0.3 \mathrm{MPa}, 0.45 \mathrm{MPa}$, and $0.6 \mathrm{MPa}$ are $3.54 \%, 3.38 \%$, and $3.25 \%$, respectively, with a minor change of $0.29 \%$. (2) Under the same impact loading pressures and stress state, freezing temperature has significant effect on the energy absorbency rate of frozen soil. For example, under impact loading pressures of $0.45 \mathrm{MPa}$, average energy absorbency rate of Group C is $21.87 \%$ at $-15^{\circ} \mathrm{C}$, which is much higher than the value of $6.4 \%$ at $-5^{\circ} \mathrm{C}$. (3) The data of Group B show that under the same test conditions, the energy absorbency rate of frozen soil under confining pressure state is higher than that under uniaxial condition, and the effect of confining pressure on energy absorbency rate is similar to that of absorbed

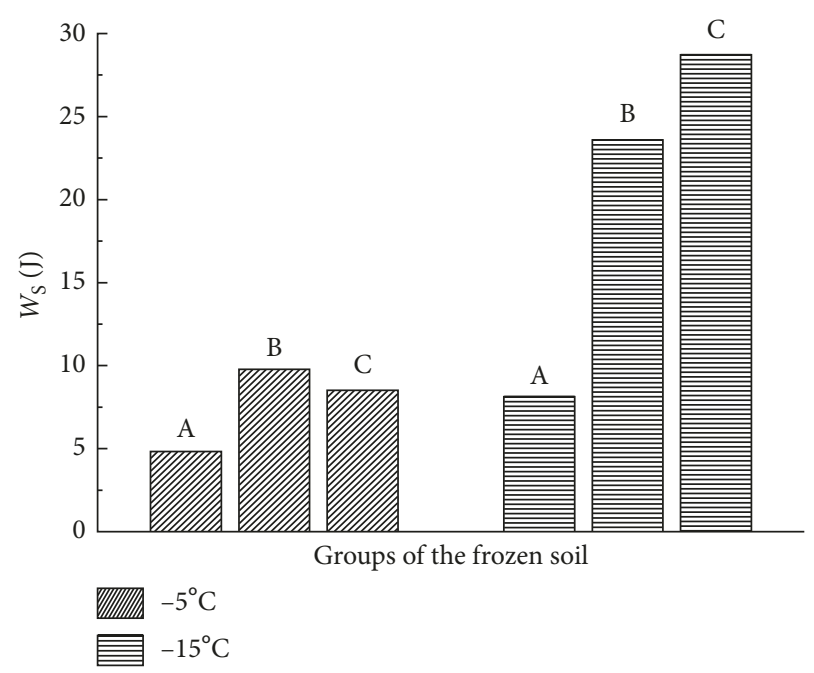

FIGURE 7: Comparison of average absorbed energy for three groups.

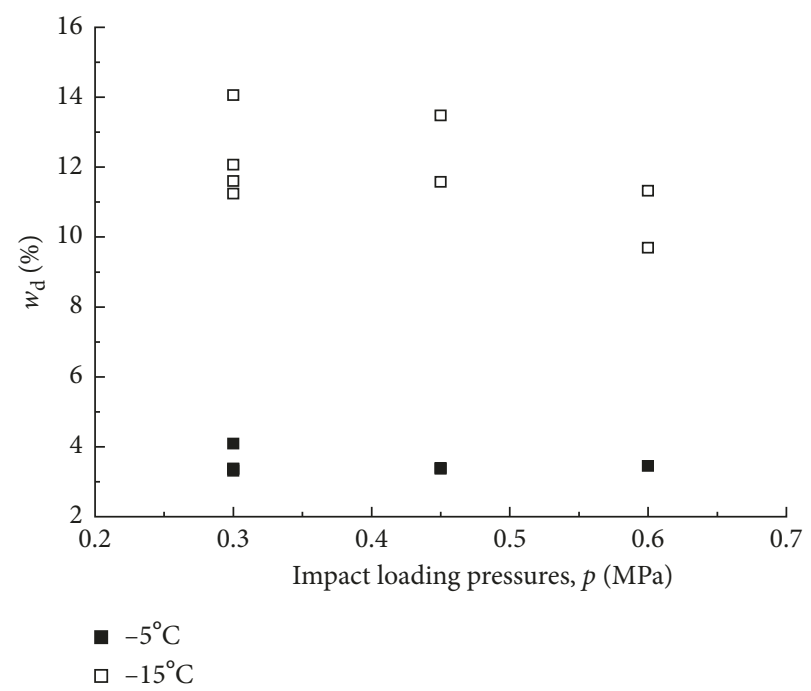

FIgURE 8: Relation between energy absorbency rate and impact loading pressures of Group A.

energy. (4) Frozen soil type affects the average value of energy absorbency rate; however, the ranking is quite different at different freezing temperatures. At $-5^{\circ} \mathrm{C}$, Group B exhibited the maximum average value of the energy absorbency rate among the three groups, but it is Group $\mathrm{C}$ at $-15^{\circ} \mathrm{C}$. Meanwhile, Group A always has the minimum values at both $-5^{\circ} \mathrm{C}$ and $-15^{\circ} \mathrm{C}$.

\section{Discussion of Absorbed Energy and Energy Absorbency Rate}

From test results, it can be concluded that both absorbed energy and energy absorbency rate are found to be negatively correlated with freezing temperature, which is in accordance with the experiment results of frozen soil [22]. The values of absorbed energy and energy absorbency rate under confining pressure are larger than the uniaxial condition. 
Meanwhile, some investigation on the effect of the confining pressure on the values of absorbed energy and energy absorbency rate for rock specimens has been carried out [23]. The critical value of confining pressure, which varies from different types of rock, has been proposed, and both absorbed energy and energy absorbency rate increase with the increase of confining pressure when the value of confining pressure is lower than the critical value of confining pressure. Moreover, the confining pressure shows downward trend when it is larger than the critical value. The impact loading pressure shows an increased effect on absorbed energy, and similar findings about the relationship between the impact loading pressure and absorbed energy are obtained in other materials (rock [11], metal [13], and porous materials $[14,15])$. Meanwhile, the impact loading pressure has less effect on the energy absorbency rate. In addition, the types of the frozen soil also affect absorbed energy and energy absorbency rate.

Frozen soil is a heterogeneous composite material, which contains joints, cracks, and natural flaws. The expansion of internal crack and the generation of new fracture surface both absorb energy, and the absorbent energy is mainly used to the expansion of internal crack and the generation of new fracture surface. The influence mechanism of freezing temperature, stress state, impact loading pressures, and frozen soil type on the energy absorption characteristics can be illustrated as follows:

(1) Frozen soil consists of four parts: mineral particles, ice inclusions, unfrozen water and gaseous inclusions. The deformation and mechanical behavior of frozen soil is complex and different from ordinary soil because of the existence of ice particles [24]. When freezing temperature decreases from $-5^{\circ} \mathrm{C}$ to $-15^{\circ} \mathrm{C}$, the content of unfrozen water decreases, the soil particles are linked together more closely, and the strength of the ice increases, which lead to more brittle characteristics of frozen soil. Hence, more cracks generate inside the frozen soil at $-15^{\circ} \mathrm{C}$ compared with that at $-5^{\circ} \mathrm{C}$, resulting that absorbed energy and energy absorbency rate of frozen soil at $-15^{\circ} \mathrm{C}$ are higher than that at $-5^{\circ} \mathrm{C}$.

(2) Many researches indicate that there has a relationship between failure mode of material and energy absorption characteristics [8]. Under the same freezing temperature and impact loading pressure, the frozen soil specimen has no obvious crack under the confining pressure of $0.5 \mathrm{MPa}$, but it breaks into fragments under the uniaxial condition. The deformation, the expansion of internal crack, and the generation of new fracture surface of frozen soil are limited under the confining pressure state compared with those under the uniaxial state. Hence, more energy is needed under the confining pressure state to reach the failure state compared with that under the uniaxial state, and both absorbed energy and energy absorbency rate increase.

(3) The effect of impact loading pressure on absorbed energy can be summarized as follows. With increasing of impact loading pressure, more cracks generate and their distribution tends to be uniform, and the absorbed energy increases.

(4) The energy absorption property of frozen soil is very complicated and shows dependence on many effect factors, such as freezing temperature, dry density, and internal structure of frozen soil, and these differences among three types of frozen soil cause the different absorbed energy and energy absorbency rate. From the test results, it is noticed that Group A always has the minimum value of absorbed energy and energy absorbency rate compared with Group B and Group C. The soil type of Group A is frozen clay, and the cohesion force between soil particles is larger compared with sandy soil and floury soil and this causes less crack generation inside frozen soil. The failure modes of Group A under different freezing temperatures are shown in Figures 9(a) and 9(b). Moreover, it is clearly noticed that Group A has no obvious crack after dynamic loading under the confining pressure state. Many previous studies indicate that unfrozen water inside frozen soil has significant influence on the property of frozen soil, and the content of unfrozen water is greatly affected by freezing temperature, type of soil, and stress state $[1,6,18]$. Scholars have conducted a series of experiments on the relationship between content of unfrozen water and freezing temperature for frozen floury soil and frozen sandy soil [1], and the test results indicate that the content of unfrozen water decreases with the decrease of freezing temperature for two types of frozen soil. For frozen sandy soil, the content of unfrozen water is $4.8 \%$ at $-5^{\circ} \mathrm{C}$, and it has little decrease when the freezing temperature decreases to $-15^{\circ} \mathrm{C}$. However, for frozen floury soil, the content of unfrozen water decreases from $13.2 \%$ to $6.4 \%$ when freezing temperature decreases from $-5^{\circ} \mathrm{C}$ to $-15^{\circ} \mathrm{C}$. It is obvious that the decrease of freezing temperature has different effects on the content of unfrozen water for two types of frozen soil. In other words, when the freezing temperature decreases from $-5^{\circ} \mathrm{C}$ to $-15^{\circ} \mathrm{C}$, the ice content has little increase for frozen sandy soil, while it has a relatively large increase for frozen floury soil. In this paper, under the same incident energy, the increase of the ice content inside frozen soil causes the increase of absorbed energy, resulting in different rankings for Group B (frozen sandy soil) and Group C (frozen floury soil) at $-5^{\circ} \mathrm{C}$ and $-15^{\circ} \mathrm{C}$. At $-5^{\circ} \mathrm{C}$, the failure modes of Group $\mathrm{C}$ is shown in Figure 9(c), and the corresponding failure modes at $-15^{\circ} \mathrm{C}$ is shown in Figure 9(d). These figures demonstrate that, at $-15^{\circ} \mathrm{C}$, Group $\mathrm{C}$ shows obvious cracks on the surface of the specimen. Under the confining pressure state, frozen soil specimens which have more damage degree absorb more energy to generate new cracks and their propagation. 


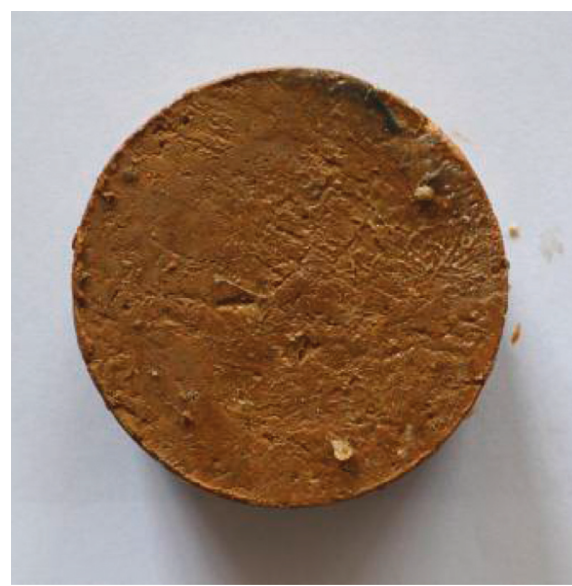

(a)

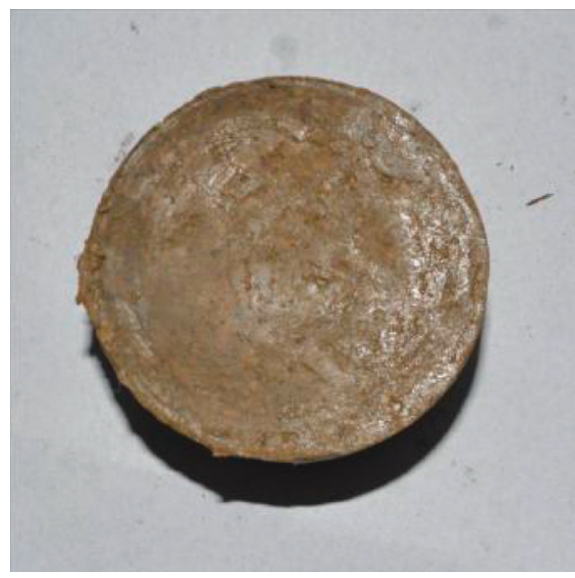

(c)

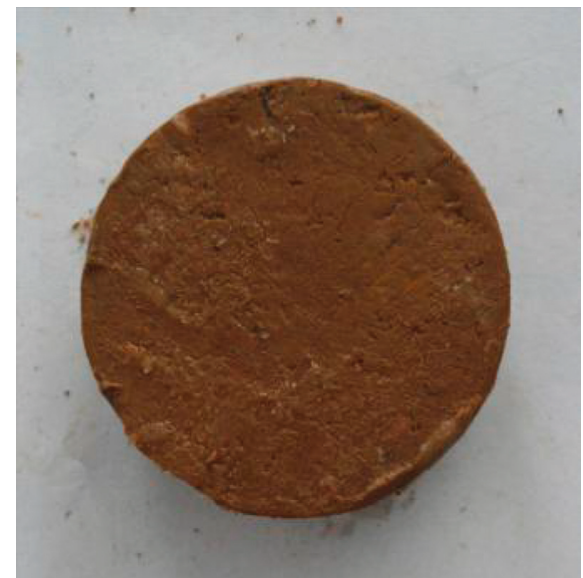

(b)

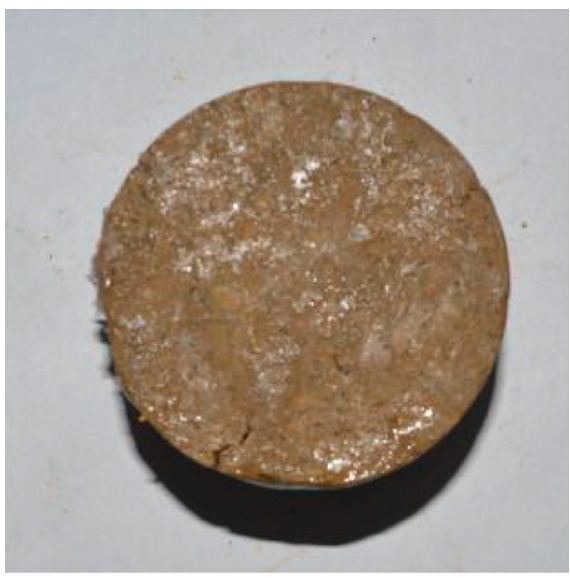

(d)

Figure 9: The failure modes of frozen soil of three groups under different test conditions. (a) Confining pressure of $0.5 \mathrm{MPa},-5^{\circ} \mathrm{C}, \mathrm{Group} \mathrm{A}$. (b) Confining pressure of $0.5 \mathrm{MPa},-15^{\circ} \mathrm{C}$, Group A. (c) Confining pressure of $0.5 \mathrm{MPa},-5^{\circ} \mathrm{C}$, Group C. (d) Confining pressure of $0.5 \mathrm{MPa}$, $-15^{\circ} \mathrm{C}$, Group C.

\section{Conclusions}

Based on SHPB tests, the effects of freezing temperature, stress state, impact loading pressures, and types of frozen soil on incident energy and energy absorption characteristics are investigated in this study. The main conclusions can be summarized as follows:

(1) Most of incident energy is reflected back to the incident bar for the relatively low wave impedance of frozen soil. The incident energy linearly increases with the increase of impact loading pressures.

(2) The absorbed energy is affected by freezing temperature, stress state, impact loading pressures, and type of frozen soil. Generally, it increases with the increase of impact loading pressures and the decrease of freezing temperature. And its value is larger under confining pressure state than that under uniaxial stress condition. The effects of value of confining pressure on absorbed energy are quite different at $-5^{\circ} \mathrm{C}$ and $-15^{\circ} \mathrm{C}$. At $-5^{\circ} \mathrm{C}$, the absorbed energy presents a change of first increase then decrease, but at $-15^{\circ} \mathrm{C}$, the absorbed energy of frozen soil increases with the increase of confining pressure.

(3) The energy absorbency rate is sensitive to the freezing temperature, the stress state, and the type of frozen soil, but it has little changes while the impact loading pressures increase from $0.3 \mathrm{MPa}$ to $0.6 \mathrm{MPa}$.

\section{Conflicts of Interest}

The authors declare that they have no conflicts of interest regarding the publication of this paper.

\section{Acknowledgments}

This research receives financial supports from the Postgraduate Innovation Fund Project in Anhui University of Science and Technology (no. 2017CX1001). The authors thank the Engineering Research Center of Underground Mine Construction, Ministry of Education, and the Anhui University of Science and Technology for providing the experiment conditions. 


\section{References}

[1] X. Z. Xu, C. J. Wang, and L. X. Zhang, Physics of Frozen Soil, Science Press, Beijing, China, 1997.

[2] Q. Y. Ma, Frozen Soil Blasting and Drilling Test and its Application, Science Press, Beijing, China, 2007.

[3] Q. Y. Ma, "Research status of dynamic properties of artificial frozen soil and its significance," Rock and Soil Mechanics, vol. 30, no. 1, pp. 10-14, 2009.

[4] Q. Y. Ma, J. S. Zhang, W. F. Chen, and P. Yuan, "Analysis of SHPB test and impact compression in confining pressure for artificial frozen soil," Rock and Soil Mechanics, vol. 35, no. 3, pp. 637-640, 2014.

[5] Q. Y. Ma, "Experimental analysis of dynamic mechanical properties for artificially frozen clay by the spilt Hopkinson pressure bar," Journal of Applied Mechanics and Technical Physics, vol. 51, no. 3, pp. 448-452, 2010.

[6] Z. W. Zhu, G. Z. Kang, Y. Ma, Q. J. Xie, D. Zhang, and J. G. Ning, "Temperature damage and constitutive model of frozen soil under dynamic loading," Mechanics of Materials, vol. 102, pp. 108-116, 2016.

[7] D. D. Ma, Q. Y. Ma, and P. Yuan, "SHPB tests and dynamic constitutive model of artificial frozen sandy clay under confining pressure and temperature state," Cold Regions Science and Technology, vol. 136, pp. 37-43, 2017.

[8] H. D. Zhang, Z. W. Zhu, S. C. Song, G. Z. Kang, and J. G. Ning, "Dynamic behavior of frozen soil under uniaxial strain and stress conditions," Applied Mathematics and Mechanics, vol. 34, no. 2, pp. 229-238, 2013.

[9] L. Y. Li, H. P. Xie, Y. Ju, X. Ma, and L. Wang, "Experimental investigations of releasable energy and dissipative energy within rock," Engineering Mechanics, vol. 28, no. 3, pp. 35-40, 2011.

[10] N. Zhou, Z. Han, J. X. Zhang, and M. Li, "Compressive deformation and energy dissipation of crushed coal gangue," Powder Technology, vol. 297, pp. 220-228, 2016.

[11] W. C. Zhu, Y. Bai, X. B. Li, and L. L. Niu, "Numerical simulation on rock failure under combined static and dynamic loading during SHPB tests," International Journal of Impact Engineering, vol. 49, pp. 142-157, 2012.

[12] Y. Deng, M. Chen, Y. Jin, and D. W. Zou, "Theoretical analysis and experimental research on the energy dissipation of rock crushing based on fractal theory," Journal of Nature Science Engineering, vol. 33, pp. 231-239, 2016.

[13] Q. Fu, Y. J. Xie, G. C. Long, D. T. Niu, and X. G. Liu, "Impact characterization and modeling of cement and asphalt mortar based on SHPB experiments," International Journal of Impact Engineering, vol. 106, pp. 44-52, 2017.

[14] Z. H. Tan, C. Chen, X. Han, and F. R. Wang, "Investigation on the dynamic compressive behavior and energy absorption properties of aluminium-silicon foam," Engineering $\mathrm{Me}$ chanics, vol. 30, no. 2, pp. 360-364, 2013.

[15] X. Luo, J. Y. Xu, E. L. Bai, and W. M. Li, "Study on the effect of basalt fiber on the energy absorption characteristics of porous material," Construction and Building Materials, vol. 68, pp. 384-390, 2014.

[16] Q. J. Xie, Q. Fu, K. R. Zheng, Q. Yuan, and H. Song, "Dynamic mechanical properties of cement and asphalt mortar based on SHPB test," Construction and Building Materials, vol. 70, pp. 217-225, 2014.

[17] V. Sujatha and C. Kishen, "Energy release rate due to friction at biomaterial interface in dams," Journal of Engineering Mechanics, vol. 129, no. 7, pp. 793-800, 2003.

[18] Y. G. Yang, F. Gao, H. M. Cheng, and P. Hou, "Energy dissipation and failure criterion of artificial frozen soil,"
Cold Regions Science and Technology, vol. 129, pp. 137-144, 2016.

[19] Y. X. Zhou, K. Xia, X. B. Li et al., "Suggested methods for determining the dynamic strength parameters and mode-I fracture toughness of rock materials," International Journal of Rock Mechanics \& Mining Sciences, vol. 49, pp. 105-112, 2012.

[20] D. J. Frew, M. J. Forrestal, and W. Chen, "Pulse shaping techniques for testing brittle materials with a split Hopkinson pressure bar," Experimental Mechanics, vol. 45, no. 2, pp. 186-195, 2005.

[21] L. L. Wang, Foundation of Stress Waves, Elsevier, Amsterdam, Netherlands, 2007.

[22] Q. J. Xie, Z. W. Zhu, and G. Z. Kang, "Dynamic stress-strain behavior of frozen soil: experiments and modeling," Cold Regions Science and Technology, vol. 106-107, pp. 153-160, 2014.

[23] J. Y. Xu, X. C. Lu, J. Zhang, J. Z. Liu, and E. L. Bai, "Research on dynamic mechanical performance of amphibolite under cyclical impact loading at different confining pressures," Journal of Vibration and Shock, vol. 29, no. 8, pp. 60-63, 2010.

[24] M. T. Chai, H. Zhang, J. M. Zhang, and Z. L. Zhang, "Effect of cement additives on unconfined compressive strength of warm and ice-rich frozen soil," Construction and Buinding Materials, vol. 149, pp. 861-868, 2017. 


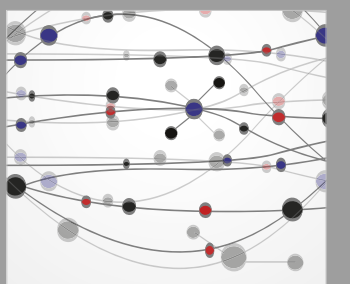

The Scientific World Journal
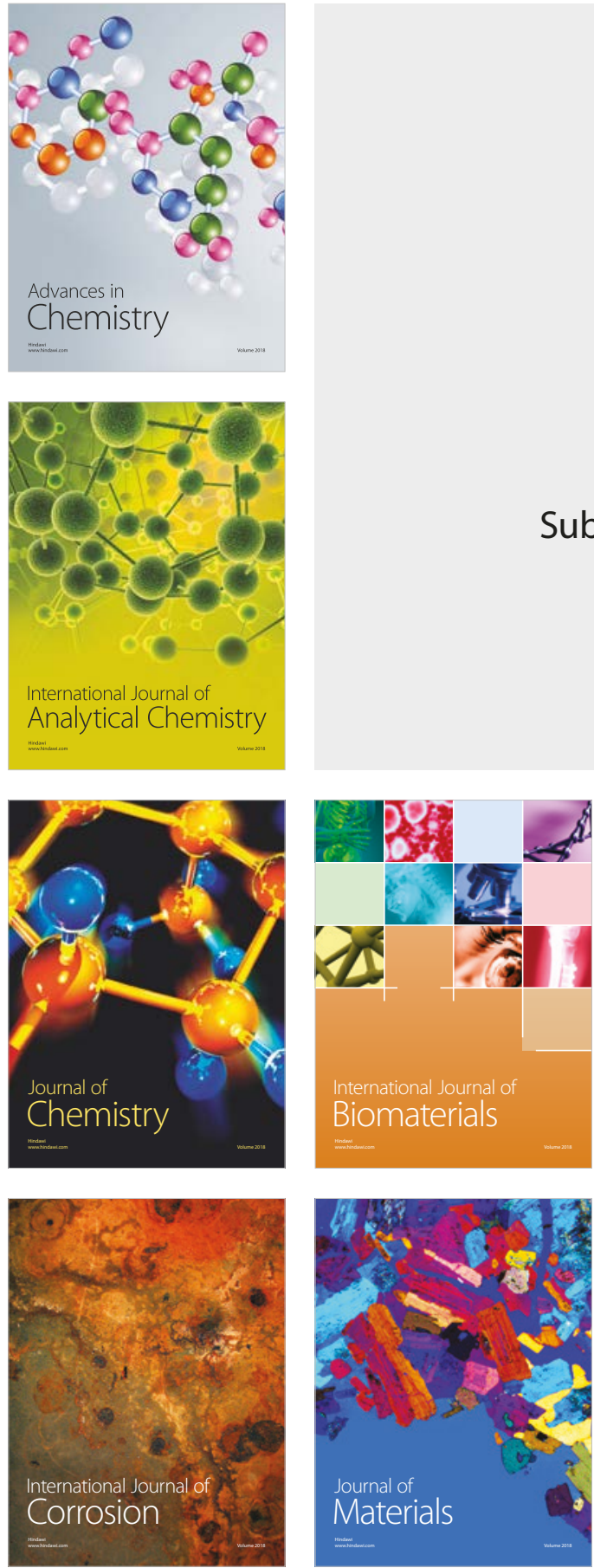

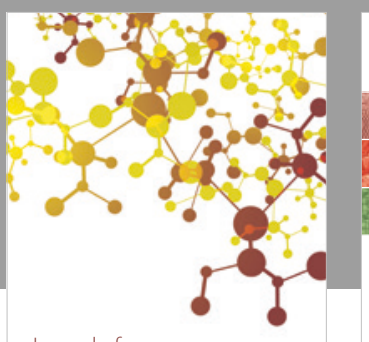

Journal of

Applied Chemistry
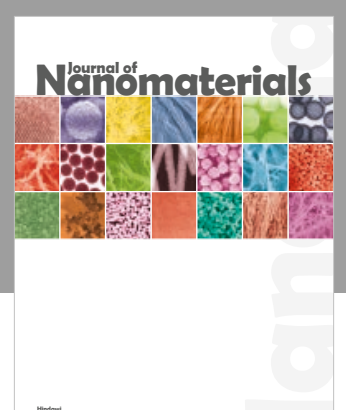

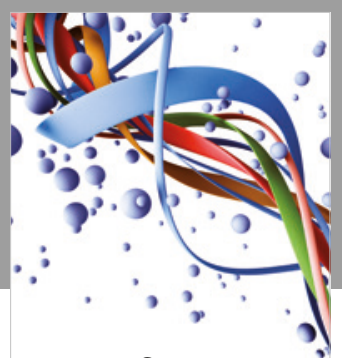

Scientifica

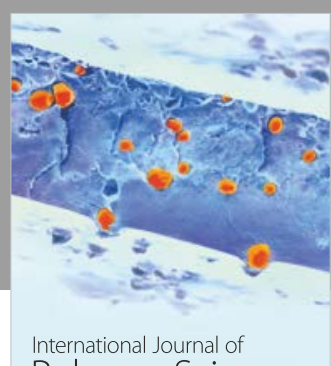

Polymer Science

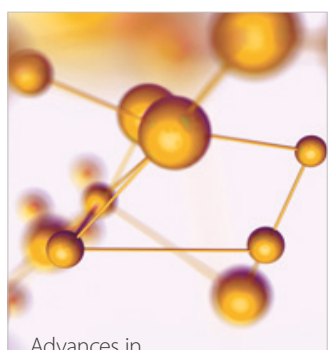

Physical Chemistry
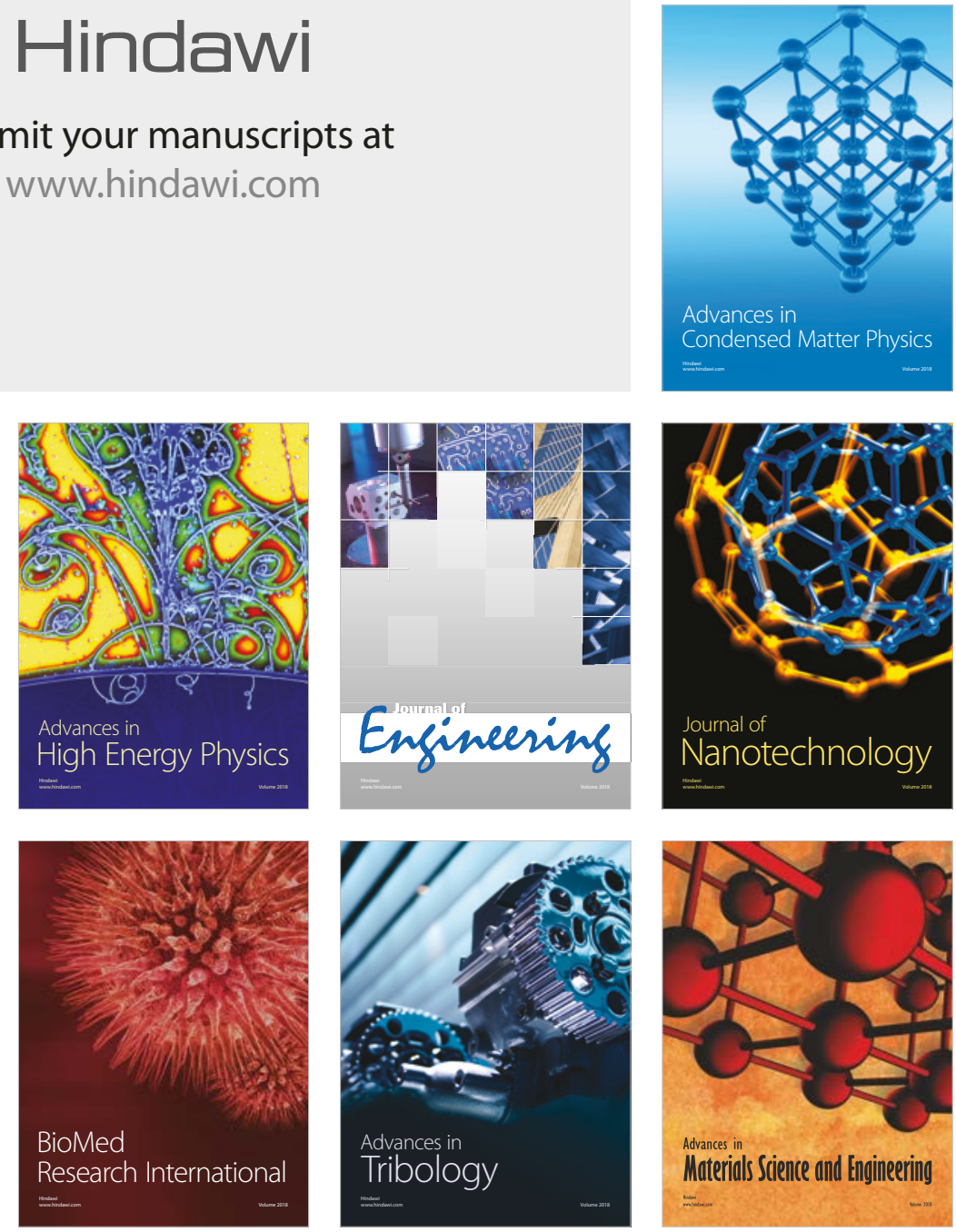